\title{
A Study about Automatic UI Construction by Interaction for the Smart Silver Generation
}

\author{
Sung Kwan Kang 1, Joon Seub Cha ${ }^{2}$ and Su Kyung Ban ${ }^{3}$ \\ ${ }^{1}$ Intersave. co., Ltd, Gwangju, Korea \\ ${ }^{2}$ Dept. of Internet Contents, Honam University, Gwangju, Korea \\ ${ }^{3}$ Dept. Social Welfare Honam University, Gwangju, Korea \\ silicon1@hanmail.net,jscha7@hotmail.com,bsk1204@hanmail.net
}

\begin{abstract}
\end{abstract}
Recently, different services are being introduced for the silver generation, but most are limited to providing information for older people and ane insufficient in terms of functionality, ease of use, and diversity.

In this paper seeks to study the design strategies of smart@pp interface for the smart silver generation born in the 70's. The proposed method intends to provide an optimized user interface by setting the icon size and spacing, font size color sound, and the psychological state in a five-step process.

An optimized interface status kalue extracted from each step is applied directly to the interface of smart app. By using the results of this study, we can expect increased accessibility and usability forsilver generation Yo use smart contents.

Keywords: New Silver App, Smart Ecosystem, Universal Design

\section{Introduction}

Since 2009, starting vith the release of I-phone in the domestic market, a wide variety of smart phones and smart devices (tablet PC, smart TV, multimedia device etc.) have appeared.

Currently the smart devices have become one of the necessities of utmost importance in daily life due to raprd expansion of smart device market internally and externally. Therefore, in the future users who are not familiar with this smart device might not have access to services available in different areas. In particular, the silver generation of people over the age of 69 willend to be alienated from the ecosystem due to physical, mental, and cultural problems.

Recently, different services are being introduced for the silver generation, but most are limited to providing information for older people and are insufficient in terms of functionality, ease of use, and diversity.

The new silver generation represented by the baby boomer generation is active, more open, and have a lot of curiosity about new things compared to the previous[1] ones. The new silver generation is interested in health, family, leisure, social participation, and digital life, and expansion of business in these areas is urgently needed[2]. Therefore, this paper seeks to study the design strategies of smart app interface for the smart silver generation born in the 70 's. 


\section{Smart silver generation}

\subsection{Concept}

In this paper, we will define separately the new silver generation to refer to the first baby boomer generation and smart silver generation to refer to the $2^{\text {nd }}$ baby boomer generation. The most visible difference between new silver generation and smart silver generation is that the smart silver generation is familiar in using the various digital devices and their contents.

Actually, the new silver generation is the generation that has been using analog devices and analog contents primarily, most of them belonging to the 50's age group as of now.

This generation is having difficulty reaching the smart ecosystem represented by smart devices due to physical, mental, and cultural issues. However, the smart/silxer/generation including the 30-40 age group has grown with and has actually participated in computer and internet generation in the 1990s, the mobile generation in the 2000s, and smart devices and the SNS society since 2010.

The generation born between 1977 and 1997 can be defined as the digital native generation. This generation, firstly defined by Marc Prensky, american education researcher, experience digital device environment such as personal computer, cellular phone, internet, MP3 since they born, and use digital language and device as a native speaker of some language [3].

Therefore, the smart silver generation is the most important consumers and producers in the hierarchy of the smart ecosystem of the future.

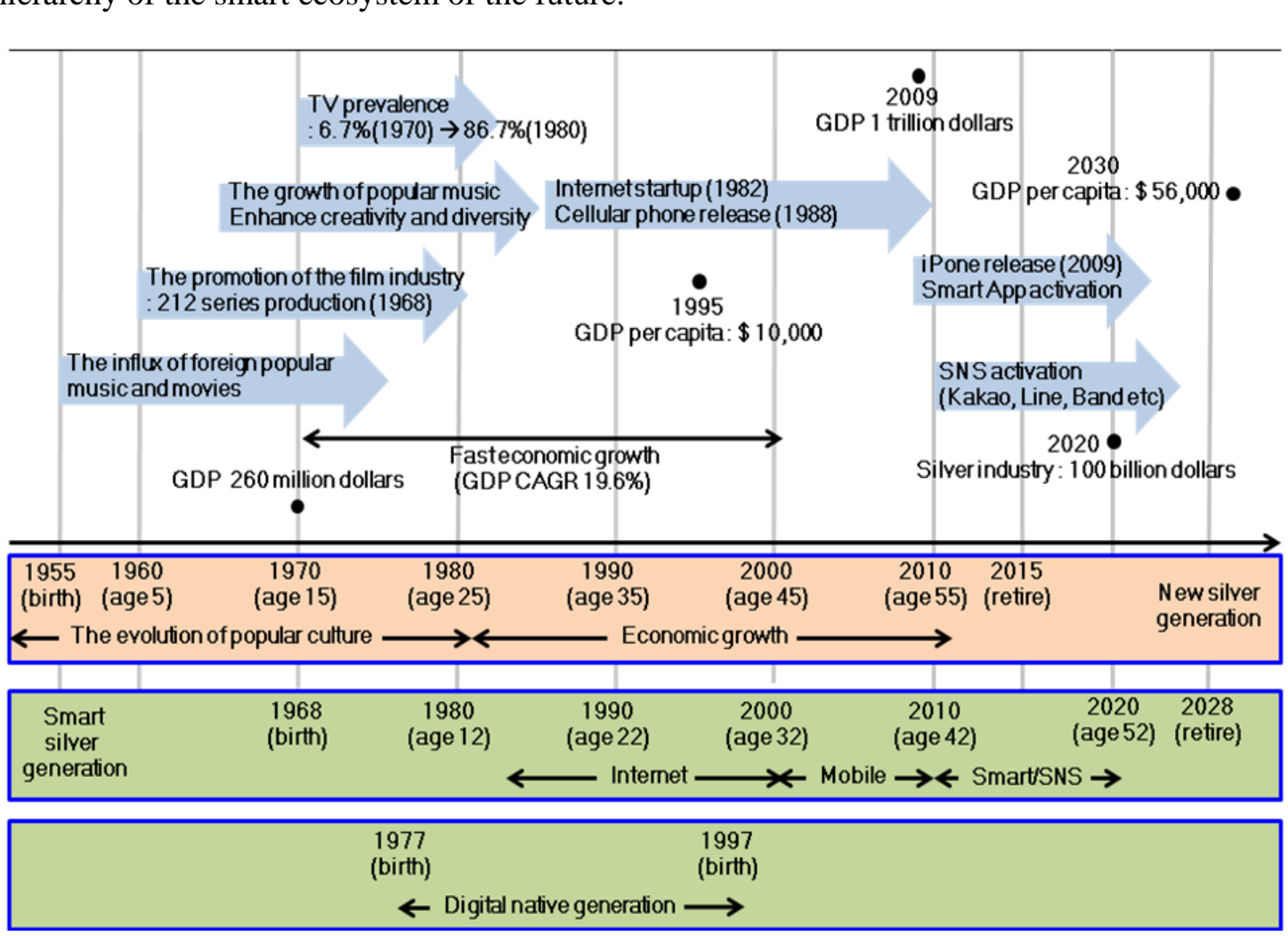

Figure 1. New silver generation and smart silver generation in Korea 


\subsection{Feature of the smart silver generation}

The smart silver generation, compared to the silver generation, is rational, positive, active, and open. In addition, they tend to try to keep personal relationships through social activities through a variety of hobbies because they have rich assets. The center of those belonging to the new silver generation is themselves or couple and they want freedom and independent design of golden years rather than living together with children.

Table 1. Compared between silver generation and new silver generation [4]

\begin{tabular}{|c|c|c|}
\hline Silver Generation & & New(Smart) Silver Generation \\
\hline Stubbornness, Conservative & Image & sitive \\
\hline $\begin{array}{l}\text { Thrifty, Simple, Limited } \\
\text { Hobbies }\end{array}$ & Way of life & \\
\hline Depend a child & Independence & dent \\
\hline Unplanned, Depend a child & Old design & lanning \\
\hline $\begin{array}{l}\text { Refused to change, Disconnect with } \\
\text { other generation }\end{array}$ & & ther \\
\hline bequeath to child & Assets & oneself, Back to society \\
\hline Among the elderly & terpersonal & Various relationship \\
\hline Child centered & Life & Couple centered \\
\hline
\end{tabular}

\section{Smart Ecosystem}

\subsection{Concept}

The mobile market which Mas previously dominated by manufacturer and the original publisher of mobile smart device is transforming to Content(C)-Platform $(\mathrm{P})$ Network(N)- Device(D) forms of smart ecosystems through introduction of a variety of smart device, advancement of internet network, contents digitalization, vitalization of App store.

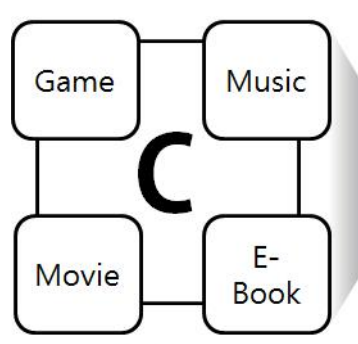

Resource (Digital contents)

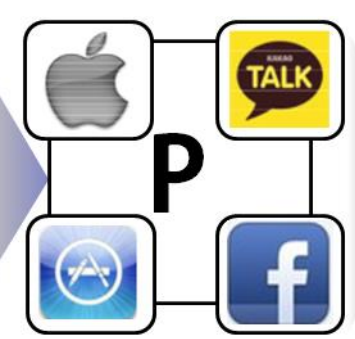

Open Market

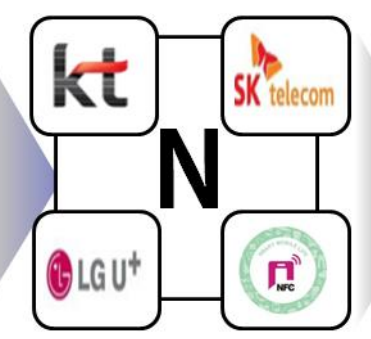

Network Infra

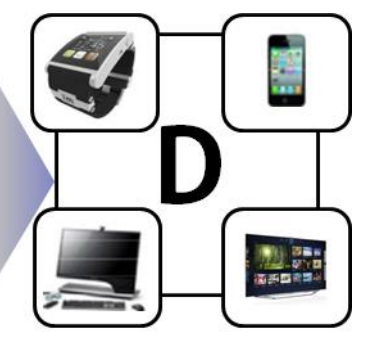

N Screen (Variable device)

Figure 2. C-P-N-D values chains

In the future, it is expected that digital contents demand is rapidly increased through platform competition and a variety of device supply and such digital content is massively consumed through IP network and followed by increased network utilization. Platform can 
tracking competition in the short term, but the competition can be intensified if you win the competition in terms of vertical integration C-D-P-N must with glass can create the largest area of interest [5].

As an example, one of recent issue of South Korea's mobile game industry is far-reaching power of platform which proven by Kakao talk's game service story. In August 2013, among the top 20 games ranked in game category of Google play, South Korea, 18 positions were occupied by Kakao game.

The difference between the Smart Ecosystem and the existing traditional IT Ecosystem is the ease of access to the global market through the growth of the mobile device, integration and fusion of different devices, and activation of open market, In addition, a new business model (mobile advertisement, smart tv contents, NFC communication, mobile book, smart watch, google glass etc.) is emerging(due to the integration of the existing analog or digital contents and the smart devices.

The current smart contents are mainly concentrated in game, music, movie, e-book, etc. and this phenomenon is expected to be maintained in the future. In addition, game device, $\mathrm{TV}, \mathrm{PC}$, and multimedia device will become part of smart devices and all network (TV network, telephone network, wireless network, internet, etc.) will be integrated under one IP.

\subsection{Smart silver generation in the smart ecosystem}

Silver generation have high exposure to decline in interlectual abilities, forgetfulness, mental illness, such as dementia as, well as physikal discomfort with age. Therefore, GUI require careful consideration an term of icon, layer, color, as one of important element that can provide outstanding convenience to silver generation [6].

In addition, it is necessary to consider universal design to help silver generation make easy to understand the structure ofthe contents and to improve cognitive capabilities. Through this, it allows to reduce the gap between the generations, help social convergence, and increase accessibility of digitâ coptent províding smart life, it can provide important basis to make silver generation an important partof smart ecosystem [7].

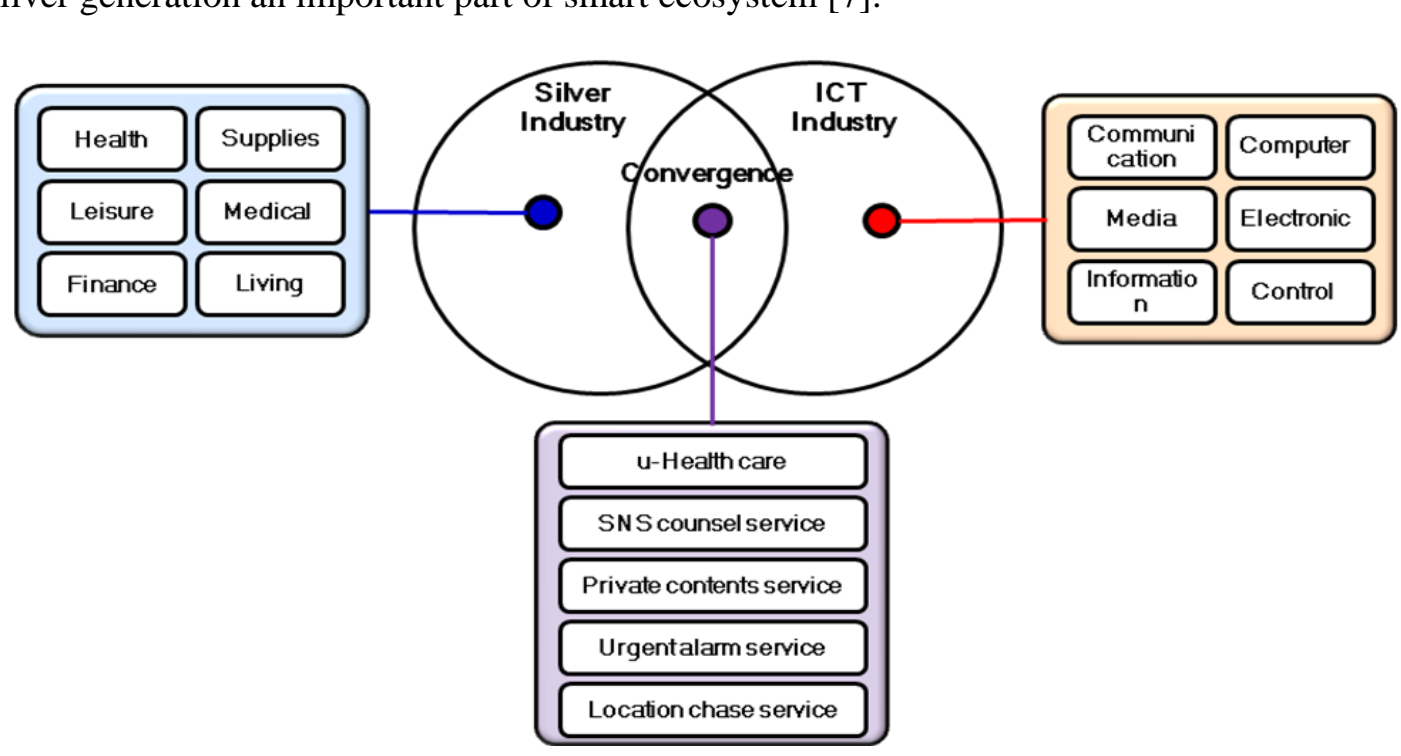

Figure 3. Convergence between the silver industry and the ICT industry

By adding function which can respond instantly to special circumstances and risk during in the silver contents make, it can provide a sense of stability and convenience. For this purpose, 
the convergent of silver industry and ICT technology is essential part, thereby, we can provide various forms of silver contents.

\section{App Interface Design for a Smart Silver Generation}

\subsection{Background}

One reason for the lack of silver contents is insufficiency of digital content utilization by elderly people. However, according to the survey of older people, it was found that older people use computer and internet for news searching, game, chatting, email, online shopping, etc. [8].

Therefore, there is high growth potential for silver industry fitting to silver gepreration as a big blue ocean industry. For example, the main consumption age group in the recent game industry is smart silver generation. Such digital contents can be one of solution to deal with various problem for older (depression, lack of interpersonal inter-generational tweaked, reduced physical ability, etc.)

Recently, functional silver generation game with the gesture recognition technology can get funny and health, and high possibility to occur aetual purchases from affordable class people can be big advantage.

The pointing behavior to control smart devices means,selecting a specific target through input devices such as mouse, joystick, and touch screen and this movement takes longer time, includes more incidental movements, and more errôrs be elder the executor is. According to study [9], the elderly people are most affected by the pointing size and the space between each pointing reduces the additional movements that reduce the psychological burden.

Table 2. Pointing related research

\begin{tabular}{|c|c|c|}
\hline Researcher & Proposed size & Margin and potion \\
\hline Colle and Hiszem [10] & $20 \mathrm{~mm}$ & no difference \\
\hline Park and Han:11] & $7 \mathrm{~mm}$ & error in the periphery \\
\hline Henze et al. [12] & $12 \mathrm{~mm}$ & - \\
\hline General icon size & $8 \mathrm{~mm}$ & $3 \mathrm{~mm}$ \\
\hline Checkbox size & $5 \mathrm{~mm}$ & - \\
\hline
\end{tabular}

\subsection{Background}

Depending on the results of these studies, this paper proposes the method of composing interface which suits the user before the use of App for the silver generation. The proposed method in this paper is to set the icon size and spacing, text size settings, color settings, sound settings, and the correction of psychological state in five steps.

Each step through the process of user test, the app over the reference value is applied to a large value, otherwise the value is automatically re-state and re-test again. Psychological test stage check user's mental state through the answers to test items to determine the psychological state and readjust user interface portion of the color or according to pre-set parameter values.

System following the proposed strategy allow user to set-up their preference at the setting part of smart device and it can be applied to all app installed in the smart device. 


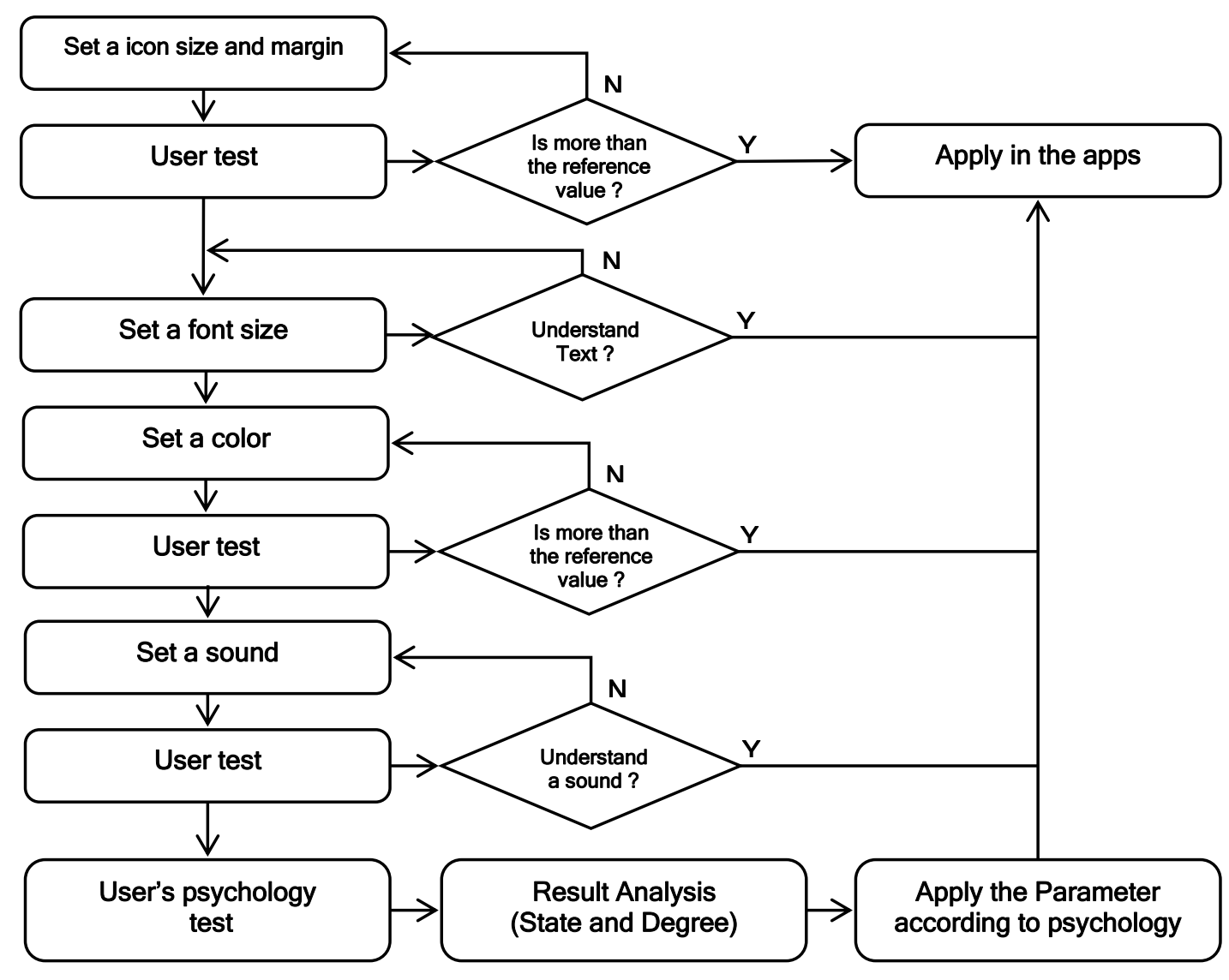

Figure 4. Proposed interface design strategy

As the 1st step set the icon sizeand margin most comfortable for the user using the initial app icon in the default size and spacing provided by the app. The type of interface, as shown in Figure 5 is used in 3 forms as in common apps. The horizontal and vertical size of icon and placement was set to the same size. W is the width and height of icon size, WM is the spacing between icons, and $\mathrm{L}$ is the horizontal and vettical size of the space in which icon is placed. The user chooses the right method of placing the icons by setting the values of $\mathrm{W}, \mathrm{WM}$, and $\mathrm{L}$.
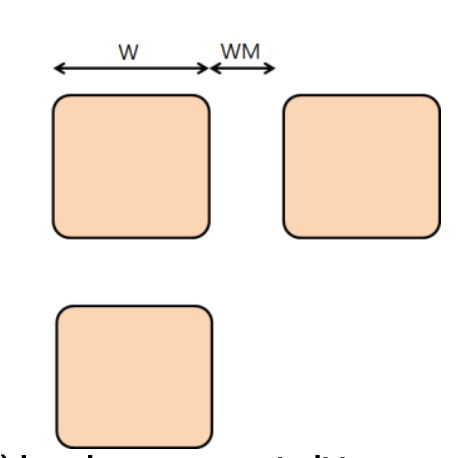

(a) Landscape or portrait type

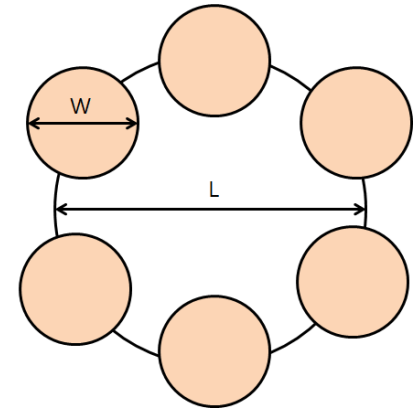

(b) Circle type

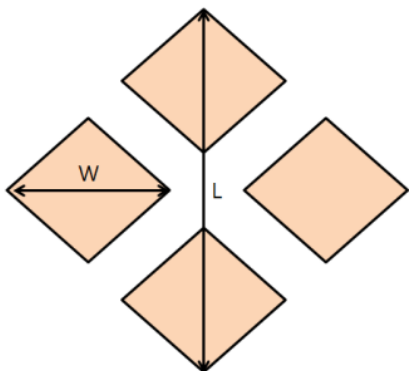

(c) Diamond Type

Figure 5. Icon array type

Initially, it check user's pointing capability through icon size, and margin status defined by the pre-set values. Next, it find optimal status value for above standard of user's pointing 
capability by changing status value to large value when test result show below than standard value. Status value found in each app is directly applied to the each app icon status.

Secondly, the user chooses the font size by showing the appropriate size of text for the previously set icon size. The user can also set the fond size of content. If the user answer that he can read the characters displayed on the screen, it is also directly applied to app.

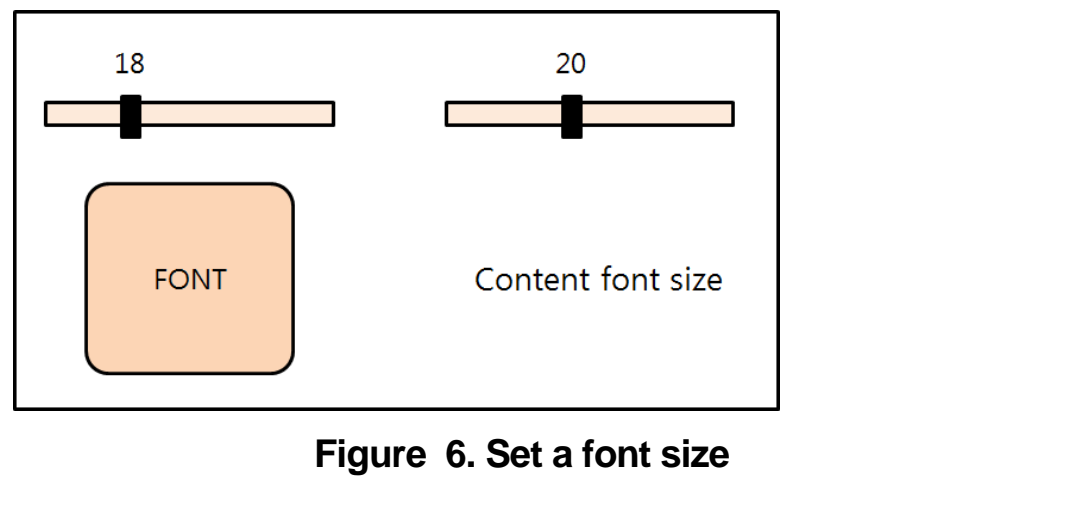

Third, a method by xrite is used for color setting m order to analyze the user's ability to identify different colors [13]. This method is a tool to denine how well the user can differentiate colors by placing similar colors together according to concentration. Depending on the result's scores of this test the icons and text colors are adjusted to suit the usen

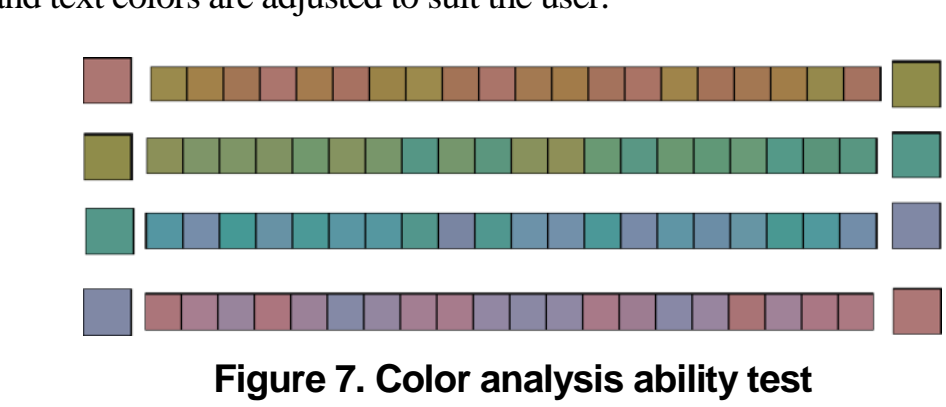

Fourth, with the soundssetting, the user chooses the right amplitude. If the user can not recognize the sound then it automatically increase amplitude and frequency, followed by retest. If the user response that he can recognize the sound then it is determined as status value. The chosen results will be applied to the sound used in the app.

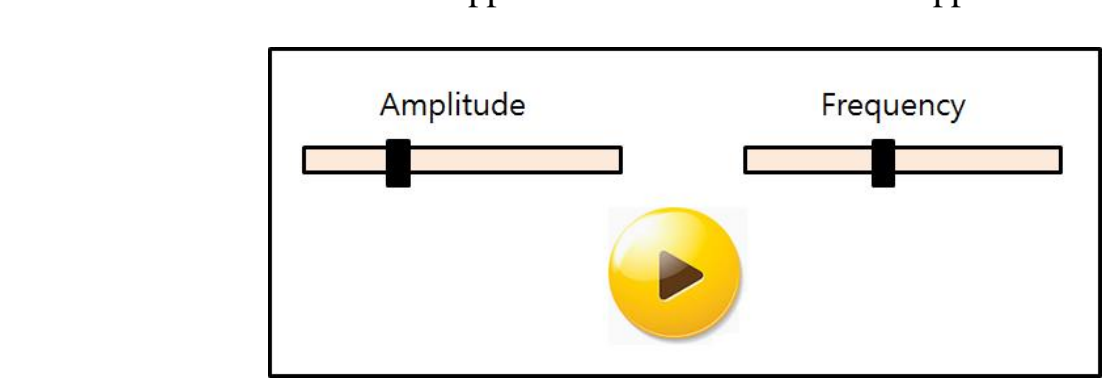

Figure 8. Hearing ability test

Finally, through the test of user's current psychological state, the appropriate color, sound, and etc. are displayed. Psychological test analyze current mental status and degree by using questions about psychological problems that often occurred in the silver generation. By using 
the test result, the pre-set weight parameter (color, sound, interface etc.) determined by psychological status is applied to app.

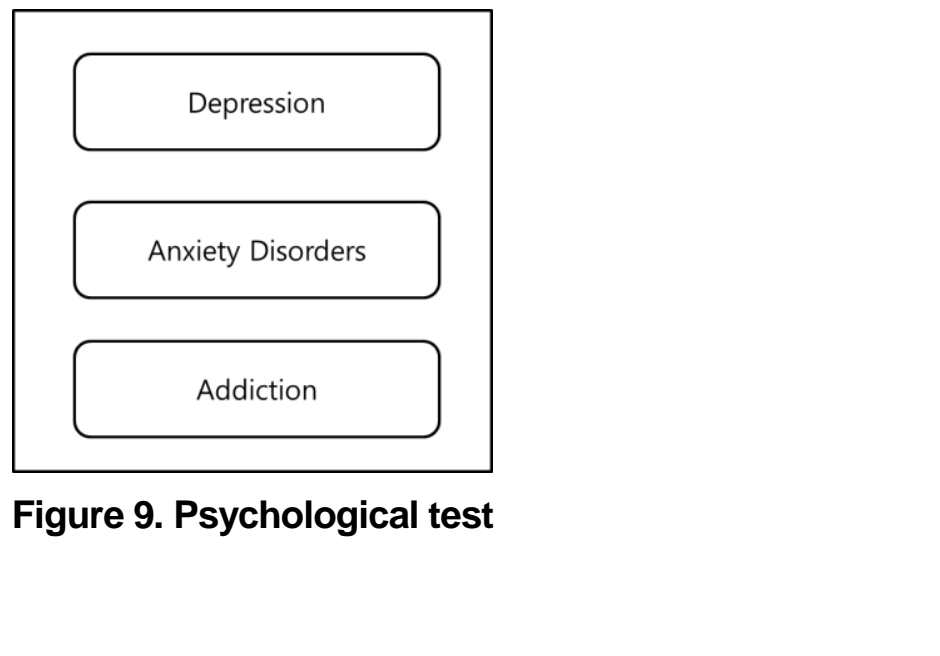

\section{Conclusion}

In the case of new silver generation, people belonging to it are more active, open and curious about new technology. Especially, the'smart silver generation is the generation that is used to various digital devices and are expected to occupy an important position in the smart ecosystem of the future.

Based on this background, this paper proposed the method of designing the smart app interface for the new silver generation. The methrd proposed intends to provide the most optimized user interface by adjusting the icon size and spacing, font size settings, color settings, sound settings, the revision of psychological state.

The method designed by this paper will be available for relocating automatically the smart phone icon and size and space of menús for app interface appropriate for the new silver generation after going through cument user's physical, perceptual, and psychological tests. It can also be used as reference material when designing app interface,

Later research will continue to realize the method proposed in this paper, and will work to standardize it through the evaluation of actual users.

\section{References}

[1] E. H. Oh, "A study about product design on the a principle of stimulation reaction coincidences in aging society", A Master's Thesis of Kookmin University, (2005).

[2] J. K. Kim "Young business for silver business", CEO Information, vol. 869, (2012).

[3] Naver encyclopedia.

[4] Shinhan Bank Report, (2012).

[5] Eugene Investment \& Securities co., Ltd. (2013), ICT market analysis (CPND ecosystem).

[6] J. S. Lee, “A study on the IHD's design directional of smart home for the silver generation”, A Master's Thesis of Kookmin University, (2012).

[7] W. H. Huh, "A study of contents design in emotional communication for new silver generation", Journal of Communication Design, vol. 39, (2012).

[8] Information divide index and research on the actual condition, National Information Society Agency, (2012).

[9] Y. S. Han, J. K. Choi, B. H. Hwang, S. M. Go, S. H. Yoon and Y. G. Ji, "A Study on Elderly for Improvement of Usability on Smartphone", The Journal of Society for e-Business Studies, vol. 17, no. 1, (2011), pp. 39-52.

[10] H. Colle and K. Hiszem, "Standing at a kiosk : effects of key size and spacing on touch screen numeric keypad performance and user preference", Ergonomics, vol. 47, no. 13, (2004), pp. 1406-1423. 
[11] Y. S. Park and S. H. Han, "Touch key design for one-handed thumb interaction with a mobile phone: Effects of touch key size and touch key location", International journal of industrial ergonomics, vol. 40, no. 1, (2010), pp. 68-76.

[12] N. Henze, E. Rukzio and S. Boll, "100,000,000 Taps : Analysis and Improvement of Touch Performance in the Large", Paper presented at the MobileHCI, (2011).

[13] http://www.xrite.com/online-color-test-challenge 130, (1993).

\section{Authors}

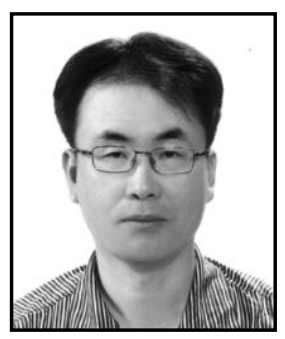

\section{Sung Kwan Kang}

He received his B.S., M.S. and Ph.D. degrees in Electronic Engineering from Chosun University, Korea, in 1997, 1999 and 2005, respectively. He has been a CTO in Intersave Co., Ltd. His research interests include game production technique, NFC technique and multimedia processing

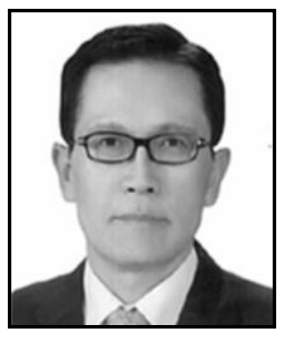

\section{Joon Seub Cha}

He received the Ph.D. degree in Management Information Systems from Wonkwang University in 1995. He is a Professor in the Departmen of Internet Contents at Honam University at Gwangju, South Korea His current research interests include System Analysis and Aesign, SmartMedia, SmartValley, SmartWork, Big Data.

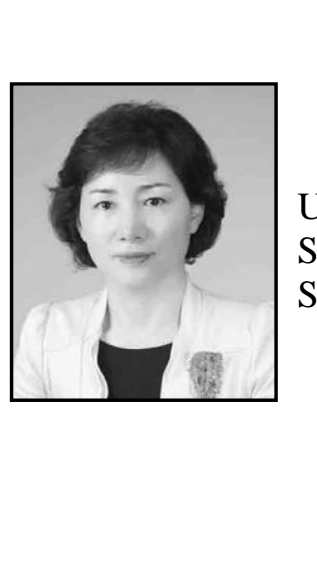

\section{Su Kyung Ban}

He gladuated the Ph.D. degree in Social Welfare from Honam University in 2010. She is a Exclusive Secretary Korean Institute of Smart Media, South Korea. Her current research interests include Silver Generation and Personality Theory, Psychology of Human 
International Journal of Multimedia and Ubiquitous Engineering Vol.9, No.4 (2014)

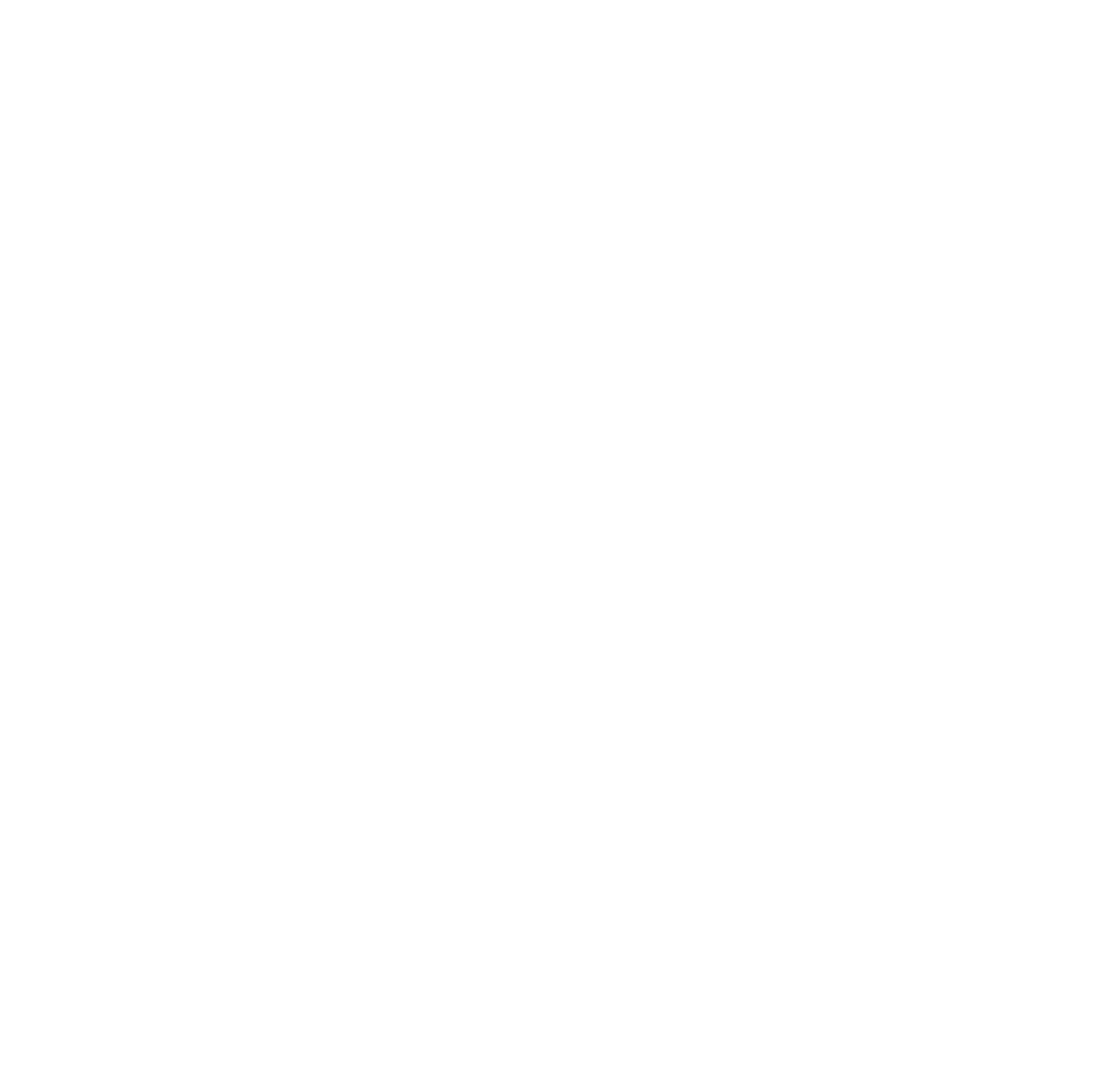

